\title{
Circulation Control Model Experimental Database for CFD Validation
}

\author{
Keith B. Paschal ${ }^{1}$, Dan H. Neuhart ${ }^{2}$, George B. Beeler ${ }^{3}$, Brian G. Allan ${ }^{3}$ \\ NASA Langley Research Center, Hampton, VA 23681
}

\begin{abstract}
A 2D circulation control wing was tested in the Basic Aerodynamic Research Tunnel at the NASA Langley Research Center. A traditional circulation control wing employs tangential blowing along the span over a trailing-edge Coanda surface for the purpose of lift augmentation. This model has been tested extensively at the Georgia Tech Research Institute for the purpose of performance documentation at various blowing rates. The current study seeks to expand on the previous work by documenting additional flow-field data needed for validation of computational fluid dynamics. Two jet momentum coefficients were tested during this entry: 0.047 and 0.114 . Boundary-layer transition was investigated and turbulent boundary layers were established on both the upper and lower surfaces of the model. Chordwise and spanwise pressure measurements were made, and tunnel sidewall pressure footprints were documented. Laser Doppler Velocimetry measurements were made on both the upper and lower surface of the model at two chordwise locations $(x / c=0.8$ and 0.9$)$ to document the state of the boundary layers near the spanwise blowing slot.
\end{abstract}

\section{Nomenclature}

$\begin{array}{ll}\alpha & =\text { angle of attack } \\ b & =\text { model span } \\ c & =\text { model chord } \\ C \mu & =\text { jet momentum coefficient, Eq. }(1) \\ C p & =\text { pressure coefficient, }\left(p-p_{\infty}\right) / q_{\infty} \\ h & =\text { slot height } \\ M & =\text { Mach number } \\ \dot{m} & =\text { mass flow rate } \\ N P R & =\text { nozzle pressure ratio, } p_{t} / p_{\infty} \\ p & =\text { pressure } \\ q & =\text { tunnel dynamic pressure, } \frac{1}{2} \rho U^{2} \\ R & =\text { trailing-edge radius } \\ S & =\text { reference area, } b c \\ T & =\text { temperature } \\ t & =\text { model thickness } \\ u & =\text { streamwise velocity } \\ U & =\text { mean streamwise velocity } \\ x & =\text { streamwise axis } \\ y & =\text { wall-normal axis } \\ z & =\text { spanwise axis }\end{array}$

\footnotetext{
${ }^{1}$ Research Scientist, Flow Physics and Controls Branch, NASA Langley Research Center, Mail Stop 170, Hampton, VA 23681-2199.

${ }^{2}$ Research Engineer, Flow Physics and Controls Branch, NASA Langley Research Center, Mail Stop 170, Hampton, VA 23681-2199.

${ }^{3}$ Research Scientist, Flow Physics and Controls Branch, NASA Langley Research Center, Mail Stop 170, Hampton, VA 23681-2199. AIAA Senior Member.
} 


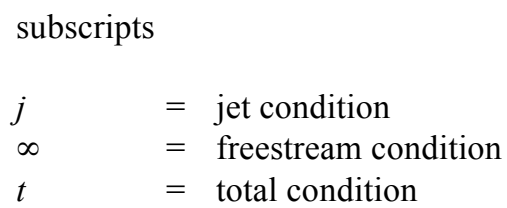

\section{Introduction}

T $\mathrm{HE}$ term circulation control wing $(\mathrm{CCW})$ typically applies to a $2 \mathrm{D}$ geometry that employs spanwise, tangential blowing through a narrow slot over a curved surface. The flow around this Coanda surface resists separation due to a balance between the sub-ambient radial pressure and centrifugal forces along the curved surface. Higher blowing rates enable this wall-bounded "jet" to stay attached farther around the elliptical surface. This effect is global, pulling the leading-edge stagnation point farther downstream and leading to increased circulation over the wing. The accurate numerical prediction of lift involves correctly modeling and/or simulating the interactions between the wall-bounded jet with both the bounding wall and the imposed freestream. ${ }^{1,2,3,4}$

The model used in this experimental study was designed and extensively tested at the Georgia Tech Research Institute (GTRI). Under the NASA Fundamental Aeronautics Subsonic Fixed Wing Project, the model has also been tested at the NASA Langley Research Center (LaRC). ${ }^{5}$ The work at GTRI was performance oriented while the work at the NASA LaRC has been geared toward flow-field documentation for code validation. The 2D model has a thickness to chord ratio of $20 \%$ and is symmetrical. The leading edge is elliptical while the rounded trailing edge incorporates tangential blowing through a spanwise slot set nominally to $0.020 \mathrm{in}$. Many numerical studies have computed the flow-field for this geometry. ${ }^{1,2,6,7}$

There are many issues that arise when generating a $\mathrm{CCW}$ database for the purpose of code validation. Previous work on conventional high-lift systems has shown that knowledge of the model boundary layer states plays a key role in accurately computing the flowfield. ${ }^{8}$ At high lift coefficients the formation of strong juncture vortices between the tunnel sidewall and the upper surface of the model contaminates the flow over the entire span by reducing circulation around the model..$^{9,10}$ In addition, a net downwash associated with high model lift and tunnel sidewall interactions effectively lowers the model angle of attack. ${ }^{2,6,7}$ The GTRI CCW model generates enough lift at moderate blowing rates to influence tunnel static pressure measurements in the Basic Aerodynamic Research Tunnel (BART); this effect must be taken into account. Documentation of the slot height can also be problematic due to the small scales involved, and lack of spanwise flow uniformity along the slot can drastically affect model circulation. One of the goals of this paper is to address, if not solve, these issues.

The behavior of the jet-flow through the slot can be sensitive to the exit conditions along the span, and documenting the boundary condition at the jet exit may be necessary. ${ }^{2,7}$ This is a difficult task due to the small scales involved. Novak published Laser Doppler Velocimetry (LDV) results on a similar circulation control model in 1986 and $1987 .{ }^{11,12}$ The model chord was approximately twice that of the current configuration and the minimum slot height was $50 \%$ greater than the GTRI nominal height of 0.020 in. A comprehensive set of measurements were obtained including LDV profiles every $10^{\circ}$ around the Coanda surface for two blowing conditions, as well as three profiles upstream of the tangential blowing.

The goal of the present study is to provide a well-documented database for code validation. This dataset will include chordwise and spanwise model pressure measurements, as well as tunnel sidewall pressure footprints. LDV will be used for boundary layer documentation and jet velocity measurement at the slot exit. To date, a transition study has been performed on the GTRI model and turbulent boundary layers established on both the upper and lower surfaces. Pressure measurements have been made for $C \mu=0.047$ and 0.114. LDV measurements have been made on the upper and lower model surfaces $(\mathrm{x} / \mathrm{c}=0.8$ and 0.9$)$ to provide boundary condition information upstream of the blowing slot.

\section{Experiment}

\section{A. Tunnel, Model and Air Delivery System}

The study is being conducted in the LaRC Basic Aerodynamic Research Tunnel (BART). The tunnel is 40 in. wide by $28 \mathrm{in}$. high and has a maximum speed on the order of $200 \mathrm{ft} / \mathrm{sec}$. For this entry the Mach number was held at 0.100 corresponding to a tunnel q of approximately $15 \mathrm{psf}$. The GTRI model has a chord of $8.6 \mathrm{in}$. and a span of $30 \mathrm{in}$., and was mounted vertically between the tunnel floor and ceiling. The tip of the model was mounted flush against the tunnel ceiling and the model root was located 2 in. beneath the floor. High-pressure air was fed through 
the model root to an internal plenum chamber and exited through a nozzle tangentially along the Coanda surface. Angle of attack, $\alpha$, was set in the absence of blowing by adjusting $\alpha$ such that symmetry was seen about the upper and lower surface $C_{p}$ distributions. Figure 1 is a cross-sectional schematic of the GTRI model and Fig. 2 is a photo of the model mounted in BART. The model dimensions are presented in Table 1.

Table 1. GTRI model dimensions

\begin{tabular}{|l|l|}
\hline chord $(c)$ & 8.6 in. \\
\hline span $(b)$ & 28 in. \\
\hline thickness $(t)$ & 1.72 in. \\
\hline trailing-edge radius $(R)$ & 0.817 in \\
\hline slot height $(h)$ & 0.020 in. \\
\hline slot t.e. thickness & 0.010 in. \\
\hline
\end{tabular}

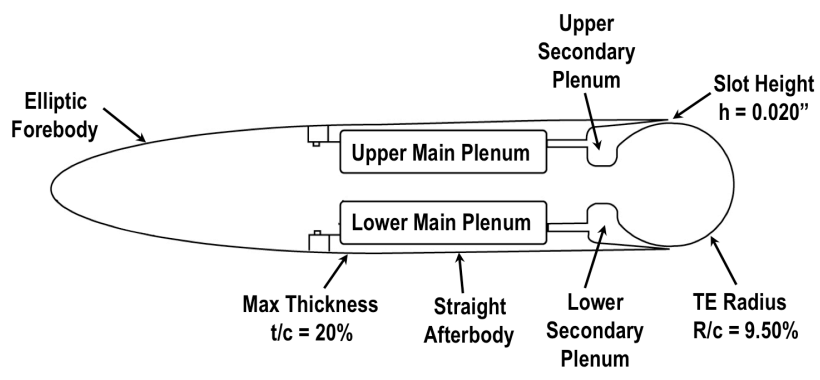

Figure 1. Schematic of the GTRI CCW.
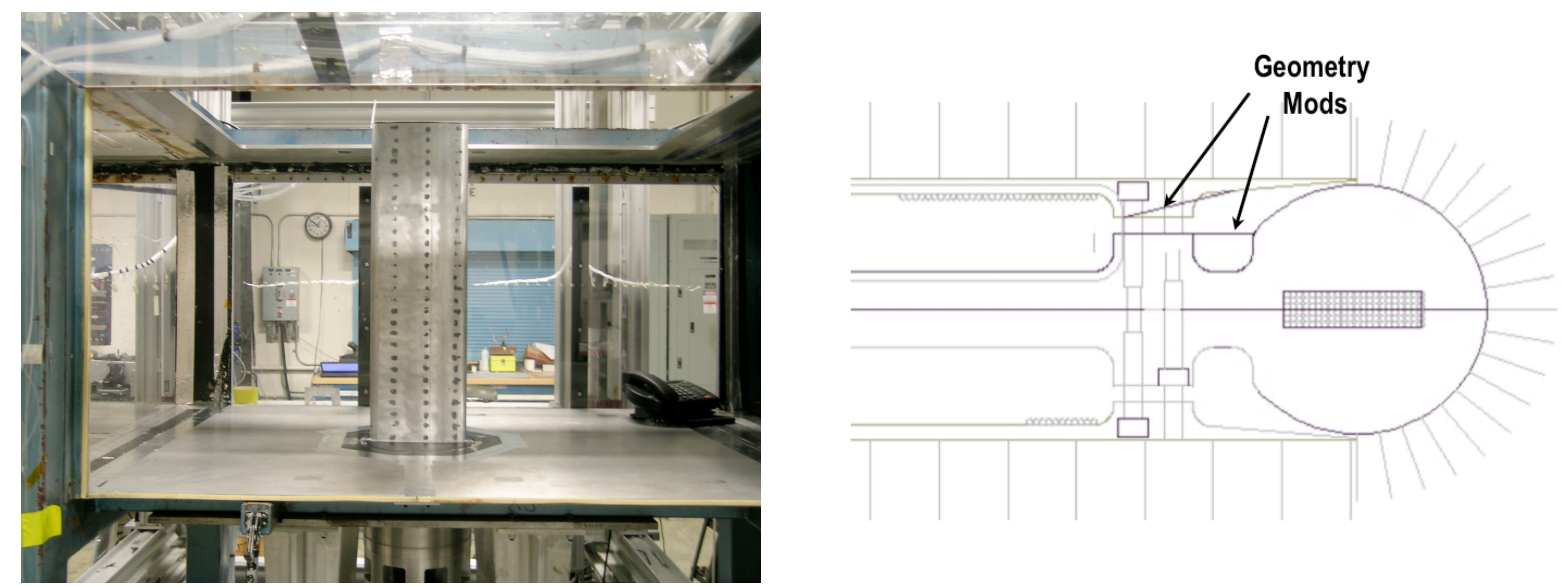

Figure 2. GTRI CCW installed in BART.

Figure 3. Geometry modifications to the upper secondary plenum.

As shown in Fig. 1, the model is symmetrical with a thickness to chord ratio of $20 \%$. The leading edge is elliptical and the trailing edge is semicircular $(\mathrm{R} / \mathrm{c}=9.50 \%)$. A number of numerical studies have used this particular geometry. ${ }^{1,2,6,7}$ For the current test the lower plenums are not being used and the gap has been closed. The secondary upper plenum has since been modified in an attempt to create a smooth nozzle geometry as shown in Fig. 3. The modified lower boundary is simply a flat surface created by adding material to the existing plenum. The modified upper boundary as drawn should be considered notional. The model may need to be disassembled and additional measurements made to determine the actual nozzle geometry.

A video measurement system was used to set the slot height. First, a 0.020 in. feeler gage reference was used to calibrate the system. Once the magnification was determined, the system was found to be repeatable to \pm 0.0003 in. The gap was then set along the span using the calibrated system. Assuming the gap setup process was equally repeatable with respect to the calibration process, a simple root mean square analysis yields an uncertainty estimate of less than $\pm 0.0005 \mathrm{in}$. per measurement. The slot height was nominally set to $0.020 \mathrm{in}$. with a minimum setting of $0.0197 \mathrm{in}$. and a maximum setting of $0.0203 \mathrm{in}$. Measurements were made every $0.5 \mathrm{in}$. along the model span.

Slot deflection under load was investigated previously at LaRC and was not repeated during this entry. The plenum total pressure had been set to approximately 27 psia and the deflection of the slot along the span measured. The average displacement was found to be 0.0006 in. During the current test, at jet momentum coefficients of 0.114 , the plenum total pressure was on the order of 18 psia.

High-pressure air delivery to the model was accomplished using shop air nominally at 120 psia. The system consisted of an isolation valve in conjunction with a pressure regulator valve. The mass-flow rate through the system was measured just upstream of the isolation valve in the high-pressure section of the system. Model temperature was 
measured well downstream just before flow entry into the model plenum. The air system plumbing was nominally 1 in. in diameter.

\section{B. Jet Characterization and Instrumentation}

Jet velocity at the slot exit was computed by isentropically expanding the flow to static conditions. Accurate measurement of the static pressure in the plane of the jet exit was difficult to obtain. There were two static pressure taps straddling the jet-exit plane, one at 50\% span and a second at $75 \%$ span, but these taps integrated over the 0.020 in. diameter of the orifice, which was on the order of the slot height. In the same manner, nozzle pressure ratio $(N P R)$ was computed using the model plenum total pressure and the tunnel static pressure. These are reference values for comparison with numerical results. Numerically it is possible to compute the true NPR and exit-plane static pressure, but it is difficult to determine these parameters experimentally.

Likewise, the jet momentum coefficient $(C \mu)$, which is a reference parameter, was based on the jet-exit velocity:

$$
C \mu=\dot{m} \cdot u_{j} /\left(q_{\infty} S\right)
$$

Mass flow was computed upstream of the pressure regulator valve in the model air delivery system. Pressures at this location varied from 110 psia to 120 psia during the test. The 25 ACFM turbine flow meter used was calibrated at $100 \mathrm{psia}$, and the turbine frequencies obtained during the test were recorded using a universal counter. Density was determined from pressure and temperature measurements made near the flow meter. Typical operating procedure during the test was to open the regulator valve slowly until the desired $C \mu$ was obtained.

Model temperature was measured in the air system plumbing just prior to entry to the model plenum. At this point the plumbing forms a right angle where the thermocouple is mounted. During the test there existed a small difference between the tunnel temperature and the model temperature. For the pressure data presented in the results section the jet flow was on the order of $4^{\circ} \mathrm{F}$ warmer than tunnel temperature.

There were three total pressure probes in the modified secondary upper plenum positioned along the span at $\mathrm{x} \sim$ 3,13 , and 27 in. These total pressures were measured with \pm 15 psid transducers. The two static pressure orifices straddling the slot-exit plane were measured with \pm 10 psid transducers. An A/D scanning board was used to record output from these five transducers, model and turbine thermocouples, and the turbine pressure transducer. The majority of the model static pressures as well as the tunnel sidewall pressures were measured with the BART electronically scanned pressure measurement system.

The uncertainty estimate for the $C p$ data presented in this paper is $0.03 .{ }^{13}$ The relevant errors that contribute to the uncertainty arose from two sources: the ESP pressure measurement system and a Mensor pressure gauge used to document tunnel pressures. The Mensor bias error was $0.01 \%$ full scale but its precision error was not statistically meaningful. The ESP total error was assumed to be $0.1 \%$ full scale. A total of 600 realizations from the ESP system were used to compute a given mean pressure on the model surface.

\section{Spanwise Flow Uniformity}

High-lift models tend to produce strong juncture vortices in the region between the upper surface of the model and the tunnel sidewall. Large favorable pressure gradients near the leading edge of the model strengthen this streamwise, vortical structure, which contaminates flow over the entire span by reducing model circulation. Previous work with conventional high-lift models has determined that removal of the tunnel sidewall boundary layer in the juncture region is an effective method to better simulate a $2 \mathrm{D}$ flow field. ${ }^{10,14}$ Blowing tubes placed in the juncture may also be used to help improve the situation. ${ }^{15,16}$ Blowing tubes were not used during the current entry of the GTRI model, but may be needed in the future in order to achieve two-dimensionality at higher jet momentum coefficients.

Non-uniform jet flow across the span can also greatly affect model circulation. Spanwise jet-flow uniformity can be estimated using the three total pressure probes located in the upper modified plenum. In addition, a "quick and dirty" survey across the middle span of the model was performed with a $0.020 \mathrm{in}$. diameter total pressure probe positioned downstream of the slot normal to, and in contact with, the surface. The wakes from the spanwise adjustment screws were discernable, but within the measurement repeatability of $\pm 0.01 \mathrm{psi}$. The results correlated fairly well with the internal probe measurements. Based on the plenum measurements, the jet velocity deviated from root to tip by $2 \%$ for both jet momentum coefficients tested. 


\section{LDV Experimental Setup}

Boundary layer profiles were measured at two $\mathrm{x} / \mathrm{c}$ locations $(0.8$ and 0.9$)$ on the upper and lower surfaces of the model using 2D LDV. The transmitting and receiving fiber-optic probes were mounted horizontally on a small optical breadboard above the BART test section. A mirror was used to rotate the beams $90^{\circ}$ down into the test section so that measurements could be made through the ceiling window over the vertical surfaces of the GTRI model (see Fig. 2 and Fig. 4).

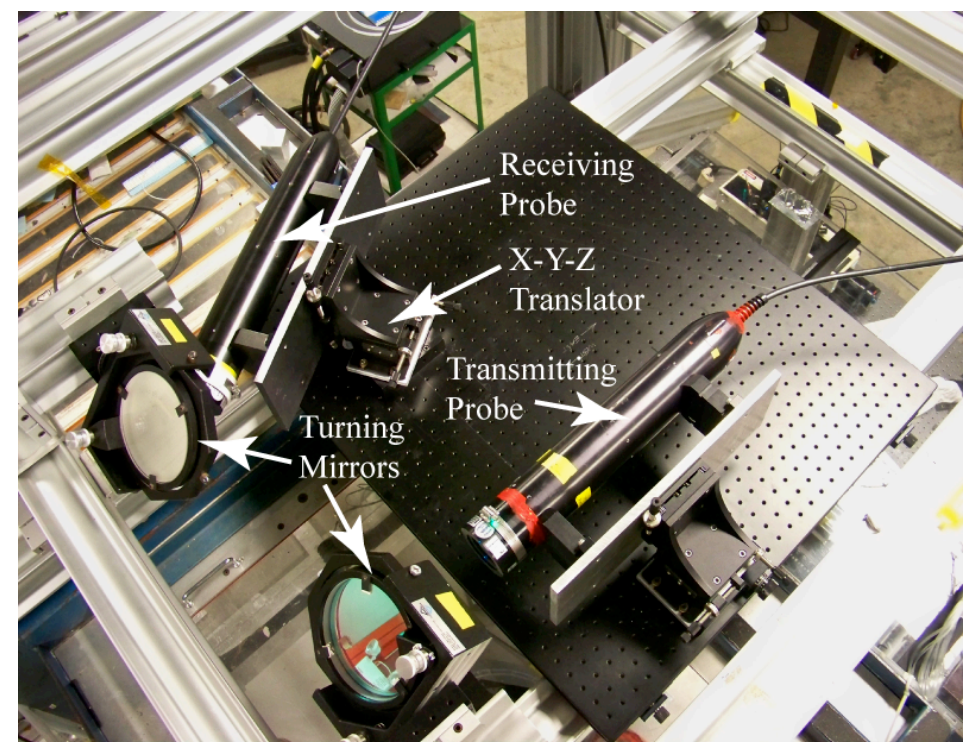

Figure 4. LDV fiber-obtic probe setup above the BART test section.

meter focal length lenses were used with both probes.

The transmitting fiber-optic probe directed four laser beams (two for each velocity component) into the test section where an ellipsoid shaped measurement volume was formed at the focus point of the four laser beams. The diameter of the measurement volume was calculated to be 0.0091 in. $(232 \mu \mathrm{m})$ and 0.0087 in. $(220$ $\mu \mathrm{m})$ for the green $(514.5 \mathrm{~nm})$ and blue $(488$ $\mathrm{nm}$ ) pairs of laser beams, respectively. The transmitting beam half-angles were about $1.4^{\circ}$. A receiving fiber-optic probe focused on the measurement volume gathered scattered light from the measurement volume and transferred the resulting signal to receiving instrumentation via a fiberoptic cable. The probe was positioned to receive scattered light at an angle of approximately $27^{\circ}$ from direct backscatter. This positioning reduced the measurement volume length from about 0.3543 in. (9 $\mathrm{mm})$ to about 0.0167 in. $(0.423 \mathrm{~mm})$. One-

The light scattered from the measurement volume was generated by seeded particles that were introduced into the freestream flow at the tunnel entrance. The seed particles were manufactured from polystyrene latex (PSL) and were nominally $36.61 \times 10^{-6}$ in. $(0.93 \mu \mathrm{m})$ in diameter. The particles were suspended in 100-proof ethanol and distributed into the tunnel flow using ultrasonic nozzles. These nozzles effectively produce a dry, seeded flow within a very short distance. Uncertainty in the velocity measurements $(u / U)$ has been estimated at 0.012 and uncertainty in the wall-normal position $(y)$ has been estimated at 0.001 in.

\section{E. Transition Study}

A transition study was performed using sublimating chemicals ${ }^{17}$ to determine: (1) the natural state of the boundary layers and (2) how best to trip the boundary layers if necessary. The model surface was treated with Naphthalene, which would sublimate at a rate based on the heat transfer between the boundary layer and the model. When performed correctly, a turbulent boundary layer would cause the Naphthalene to sublimate while a laminar boundary layer would not. Natural transition to turbulence was not seen on the lower surface for any blowing condition, and upper surface natural transition depended on the blowing rate. Natural transition on the upper surface occurred at approximately $20-25 \%$ chord for $C \mu \sim 0.100$, near the leading edge for $C \mu \sim 0.150$, and a laminar bubble was seen at the leading edge for $C \mu \sim 0.185$. Based on these results, the decision was made to trip both surfaces.

The trips were placed downstream of the upper and lower surface suction peaks using the chordwise pressure profiles as a guide. Braslow's critical height method for distributed roughness induced boundary layer transition was used to determine an initial height for the trip. ${ }^{18}$ Although this method assumes a flat-plate boundary layer in the absence of a pressure gradient, it was sufficient for determining a starting place for the trip study. Figure 5 shows the upper surface of the GTRI model with various sized trip dots for $C \mu=0.050$. The flow is from left to right. The first row of dots is $0.167 \mathrm{in}$. from the leading edge (lower portion of the figure) and the second row is $0.328 \mathrm{in}$. from the leading edge. The 0.004 in. dot has no effect on the laminar boundary layer. A turbulent wake develops behind both the 0.006 in. and $0.0072 \mathrm{in}$. dots and becomes a transition wedge downstream. Both the 0.008 and 0.010 in. dots immediately produce a transition wedge.

Similar results were seen for $C \mu=0.012$ on the upper surface. For jet momentum coefficients above 0.185 a laminar separation bubble was observed on the upper surface leading edge. Figure 6 shows the row of dots used to 
Figure 5. Effect of dot height on transition for $\mathrm{C} \boldsymbol{\mu}=\mathbf{0 . 0 5 0}$.

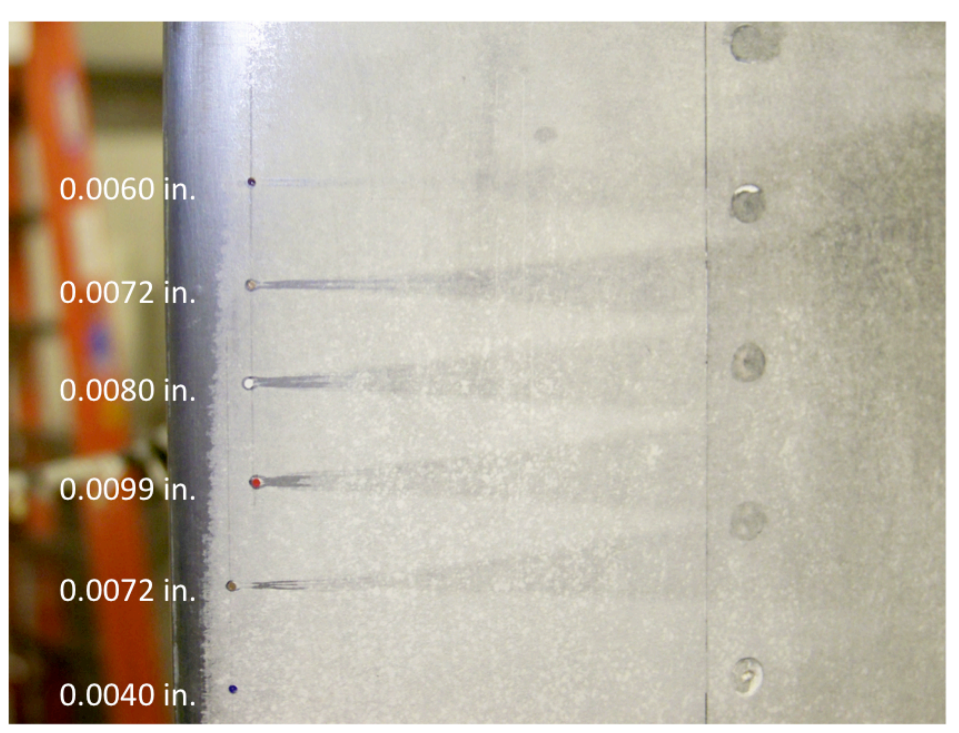

trip the upper surface boundary layer for this test entry. The row of 0.008 in. dots was placed approximately 0.328 in. downstream of the leading edge. The photo suggests the formation of spanwise vortical structures that scrub the naphthalene from the surface of the model and promote transition to a turbulent boundary layer.

It was not possible to trip the lower surface boundary layer with our suite of dots. The largest dot acquired for this entry was $0.010 \mathrm{in}$. and this height was not sufficient to transition the lower surface boundary layer. In place of the dots, zigzag tape was used to trip the lower surface. In addition, due to the favorable pressure gradient (Fig. 10), the boundary layer was tripped further downstream at approximately $2.315 \mathrm{in}$. from the leading edge. In Fig. 7 the flow is from right to left and the white, $0.012 \mathrm{in}$. height zig-zag tape used to trip the boundary layer can be seen $(C \mu \sim 0.050)$. In this case there is a distinct transition line behind the tape where the naphthalene has been scrubbed from the surface. The naphthalene upstream of the tape suggests the presence of a laminar boundary layer. Note the transition wedges seen over the protective tape covering the pressure orifices. Similar results were seen for $C \mu \sim$ 0.120 .

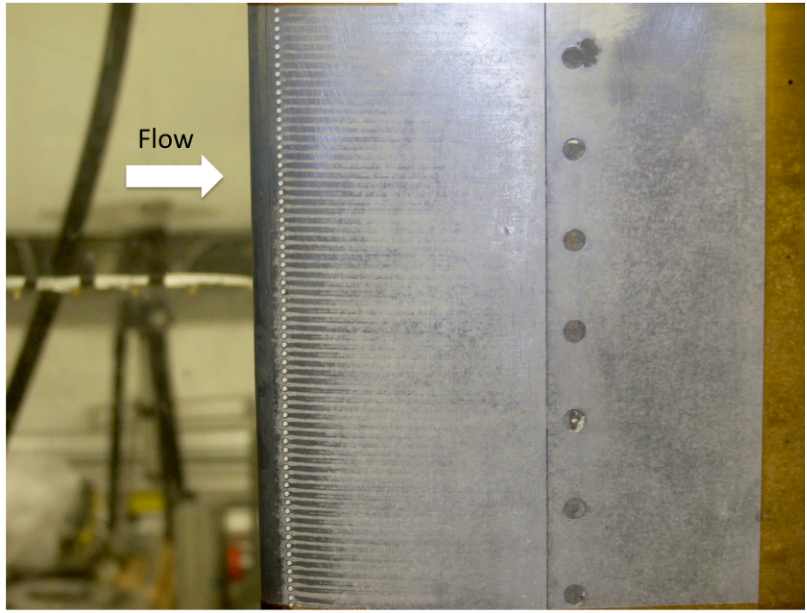

Figure 6. Transition on the upper surface $\mathrm{C} \boldsymbol{\mu}=\mathbf{0 . 0 5 0}$.

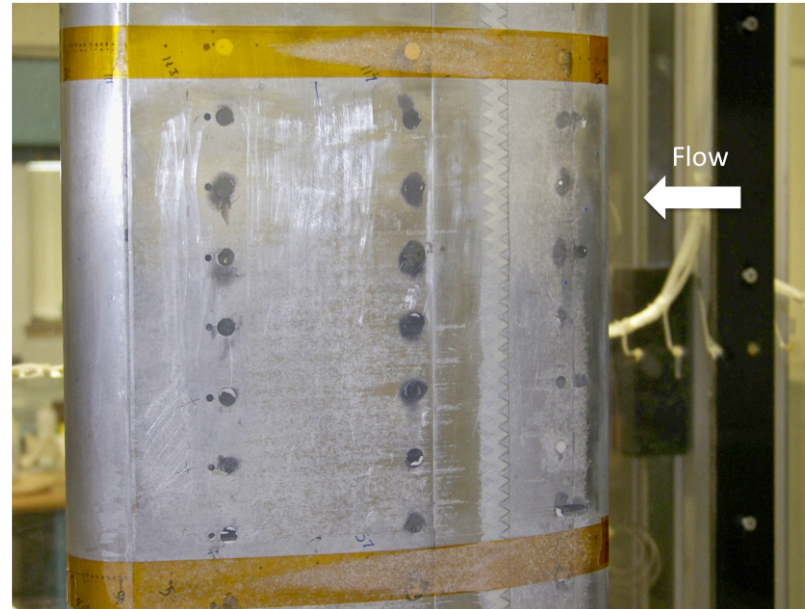

Figure 7. Transition on the lower surface $\mathbf{C} \boldsymbol{\mu}=\mathbf{0 . 0 5 0}$.

\section{Results}

Spanwise pressure distributions are presented in Fig. 8. Experimental data are shown plotted against 3D numerical results (compressible RANS solution from the OVERFLOW $\operatorname{code}^{7}$ ). The spanwise row is located at $\mathrm{x} / \mathrm{c}=$ 0.69. The general trend in the data across the span is to be expected due to the augmentation of the streamwise, vortical juncture flow by the separation of the tunnel sidewall boundary layers. The trend is exaggerated with higher blowing rates through the slot. It may be necessary to add blowing tubes in the sidewall juncture region to reduce this effect at higher jet momentum coefficients.

An important difference between the numerical study and the experiment is the modification of the secondary upper plenum as shown in Fig. 3. The numerical study was conducted using the old geometry, and the jet conditions 
were computed using initial flow conditions $\left(p_{t}\right.$ and $\left.T_{t}\right)$ introduced in the main plenum chamber. ${ }^{7}$ The experimental total pressure was actually measured in the secondary plenum. The initial flow conditions used in the numerical study were taken from a preliminary test of the GTRI model in 2009. ${ }^{7}$ Figure 9 is a comparison of mass-flow rate versus $N P R$ for the experimental and numerical studies. In the plot, the lower NPRs correspond to a momentum coefficient of 0.047 and the higher NPRs correspond to a momentum coefficient of 0.114 .

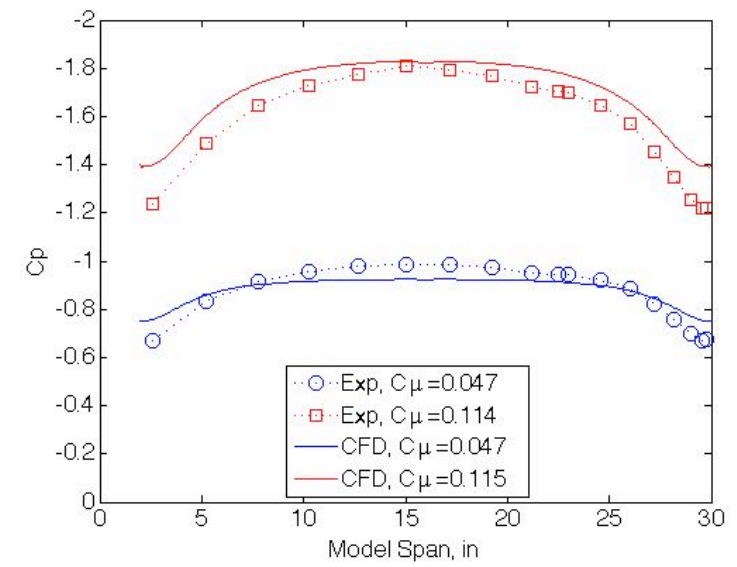

Figure 8. Spanwise $C p$ distributions, Experiment vs. CFD, $x / c=0.69$.

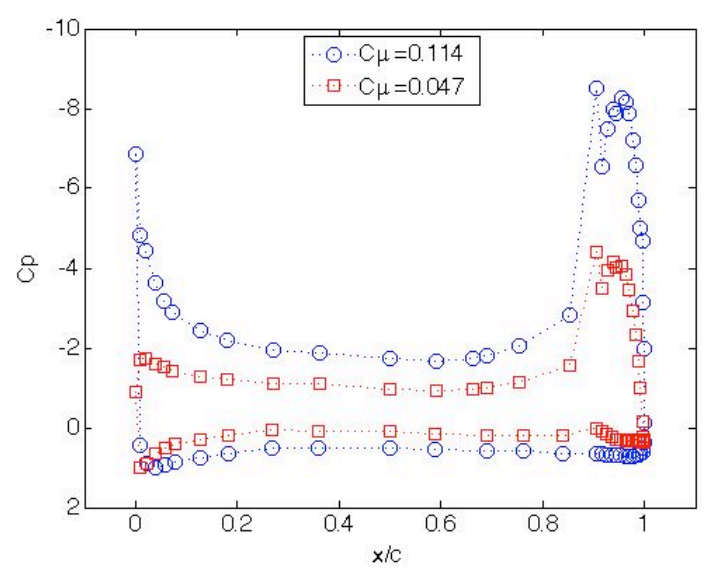

Figure 10. 50\% span chordwise $C_{p}$ distributions.

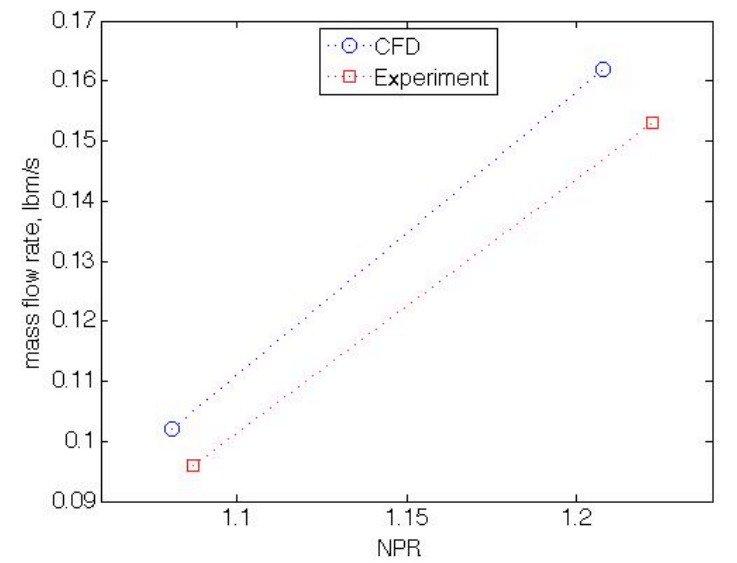

Figure 9. Comparison of the air delivery system performance between Exp and CFD.

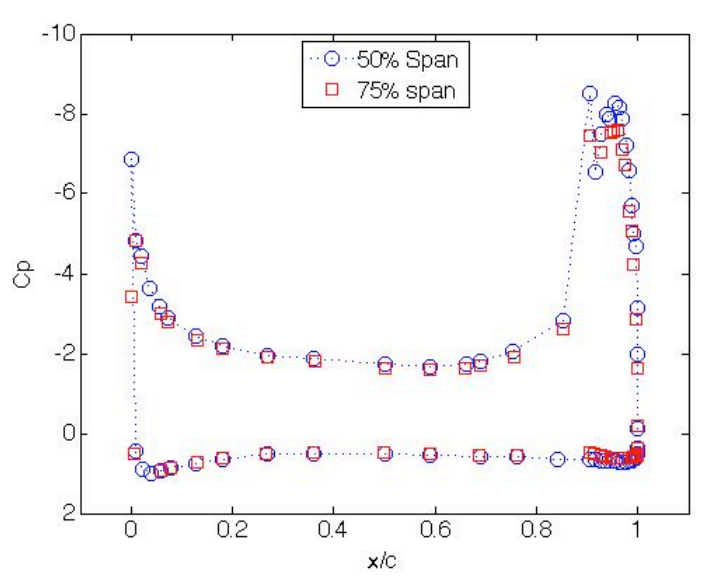

Figure 11. Chordwise $C p$ distributions at $C \mu=0.114$.

The chordwise pressure distributions at 50\% span for both jet momentum coefficients are presented in Fig. 10 . The pressure spike near the trailing edge is from the pressure port that straddles the slot lip on the upper surface (x/c $=0.905)$. The flow exiting the slot around the Coanda surface is consistent with the trend published by Allan. ${ }^{7}$ Chordwise pressure distributions at both spanwise locations are presented in Fig. 11 for the higher $C \mu$. The differences are not unexpected given the variation in lift across the model span (Fig. 8.). Lower velocities are seen at both the leading and trailing edges of the model along the $75 \%$ spanwise row. It appears that the location of the upper surface suction peak has shifted as well.

A direct comparison between the experiment and 2D compressible RANS ${ }^{7}$ is shown in Fig. 12 for the higher blowing case. The numerical results are compared with the 50\% span chordwise data from the experiment. For the numerical results the Shear Stress Transport (SST) turbulence model was used and a Rotational/Curvature Correction (RCC) model was implemented in OVERFLOW. The overall agreement is good. For this numerical case the initial flow conditions matched those of the current study. The mass-flow rates between the experiment and the numerical results differed on the order of $6 \%$ in order to match $C \mu$. The change in internal geometry or the application of the initial flow conditions in the primary plenum may be the cause of this difference. 


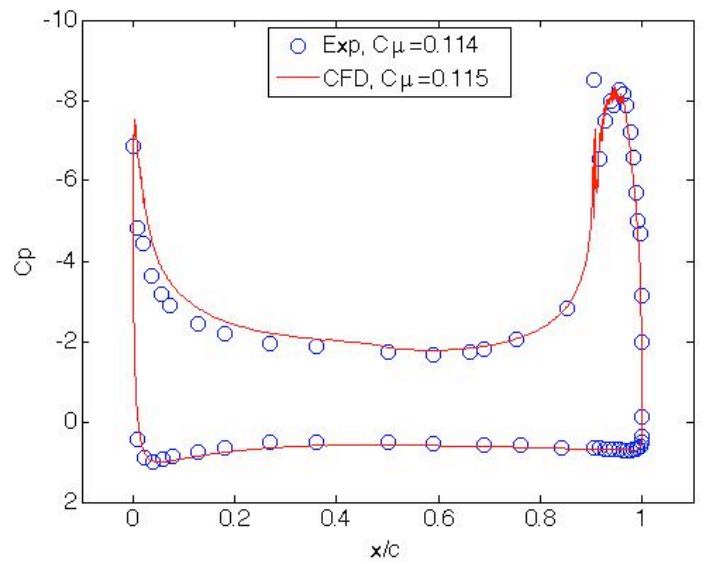

Figure 12. Comparison of $C p$ distributions between CFD and Exp.

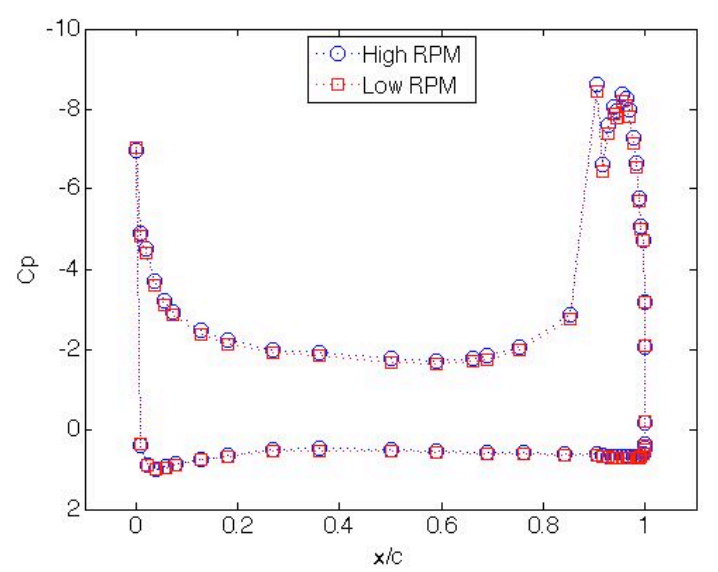

Figure 14. Effect of model circulation propagated through to $50 \%$ span $C p$ distributions $(C \mu=0.114)$.

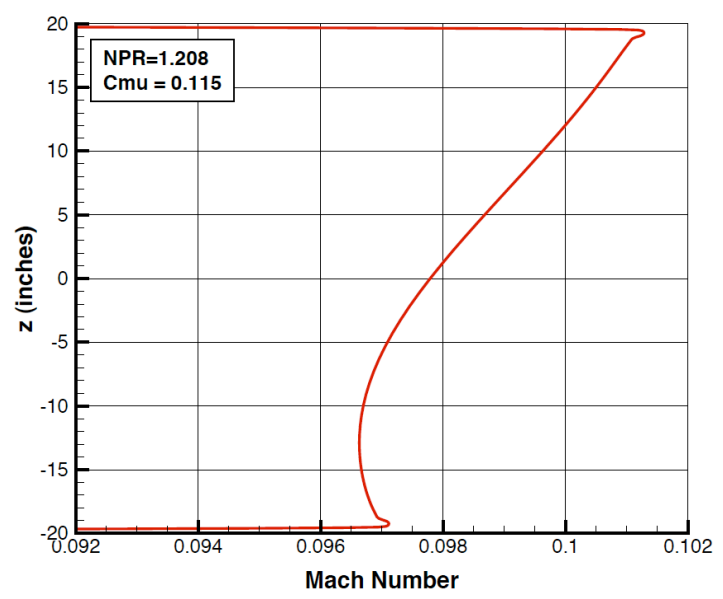

Figure 13. Velocity gradient at test section entrance.

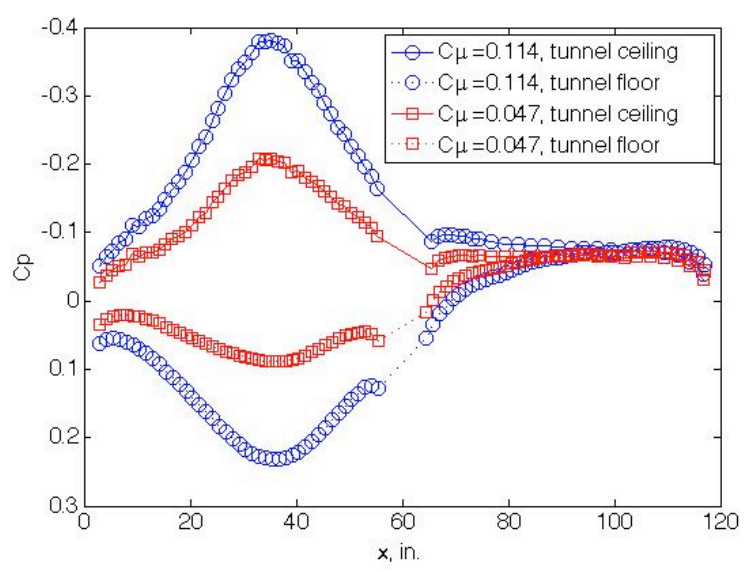

Figure 15. Pressure footprints on the tunnel sidewalls.

The large circulation field of the model affected the tunnel static pressure measurements and this effect increased with higher blowing rates. The static pressure is measured at the entrance of the test section on each of the four walls and all four ports are physically plumbed together. The 3D numerical prediction for the velocity gradient ${ }^{7}$ at the test section entrance is shown in Fig. 13. To investigate this effect, runs were made measuring the pressure at only one static port at a time. The port on the tunnel "floor" experienced an upstream velocity component due to model circulation and the tunnel was required to run at a higher RPM to compensate given a fixed Mach number. The port on the tunnel "ceiling" experienced a downstream velocity component and the opposite effect was observed. A comparison between the two runs is shown in Fig. 14 for $C \mu=0.114$.

An estimate of the offset in the two curves shown in Fig. 14 was made by computing the average difference along the row of spanwise pressure ports at $\mathrm{x} / \mathrm{c}=0.69$. For the lower jet momentum coefficient the difference was on the order of 0.025 and for the higher blowing case the difference was on the order of 0.080 . Given the somewhat linear gradient at the test section entrance, averaging the two runs is a reasonable way to reduce the effect. Note that the uncertainty in $C p$ is on the order of 0.030 .

Figure 15 presents the tunnel pressure footprint for both blowing conditions as seen on the tunnel sidewalls. The large discontinuities in the data at $\mathrm{x} \sim 60$ in. are a result of the junction between the two distinct test sections. The forward and rear test sections are separated by a metal spar centered at $\mathrm{x} \sim 60 \mathrm{in}$. The model was mounted vertically in the forward test section and the tunnel sidewalls were instrumented with static pressure ports. The smaller steps in each streamwise pressure distribution, near the metal spar, are due to surface discontinuities between the glass 
sidewalls and the support structure. Tunnel empty measurements are planned for a future entry. Subtracting tunnel empty measurements from the baseline footprint will allow for a better comparison with numerical results.

To document the state of the boundary layers, 2D LDV measurements were made on the upper and lower surfaces of the model at $\mathrm{x} / \mathrm{c}$ locations of 0.8 and 0.9. The resulting profiles are presented in Figs. 16-19. On the upper surface of the model the velocity profiles are seen to distort and the flow to accelerate near the trailing edge of the slot at $\mathrm{x} / \mathrm{c}=0.905$ (Figs. 16-17). The lower surface profiles more closely resemble those of a canonical turbulent boundary layer (Figs 18-19). Note the significant increase in circulation for the higher jet momentum case. For $C \mu=$ 0.115 , the upper surface velocities increase while the lower surface velocities decrease relative to the lower blowing condition. Comparison with numerical studies ${ }^{2}$ is ongoing and preliminary comparisons have been favorable.

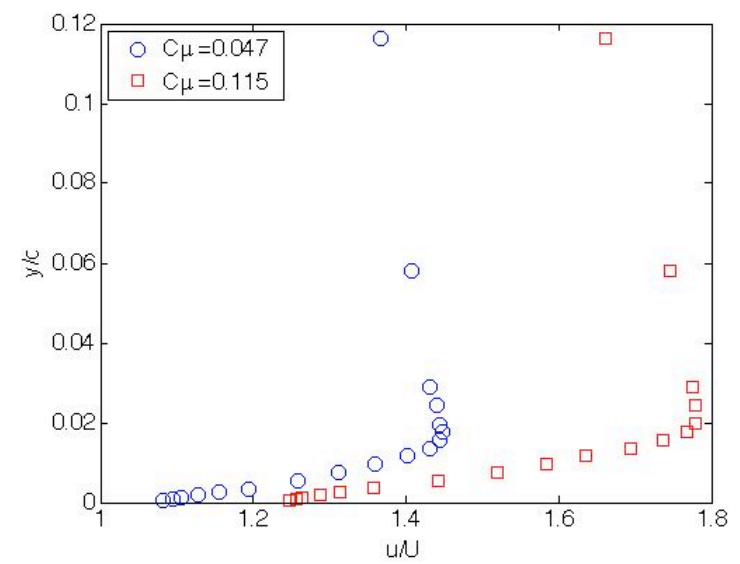

Figure 16. LDV boundary layer profiles, upper surface, $\mathbf{x} / \mathbf{c}=\mathbf{0 . 8}$.

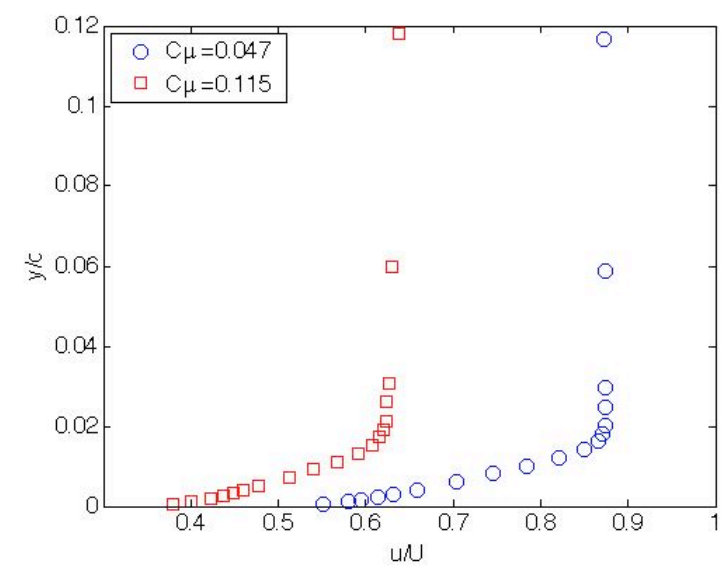

Figure 18. LDV boundary layer profiles, lower surface, $\mathbf{x} / \mathbf{c}=\mathbf{0 . 8}$

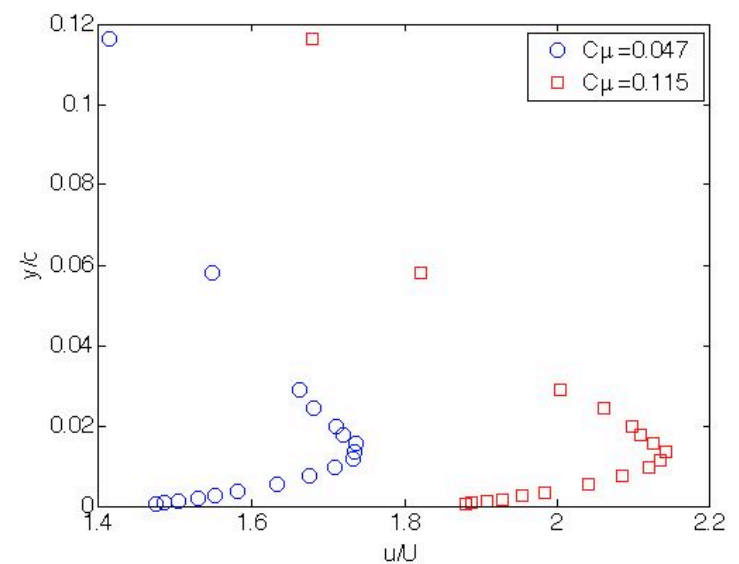

Figure 17. LDV boundary layer profiles, upper surface, $\mathbf{x} / \mathbf{c}=\mathbf{0 . 9}$.

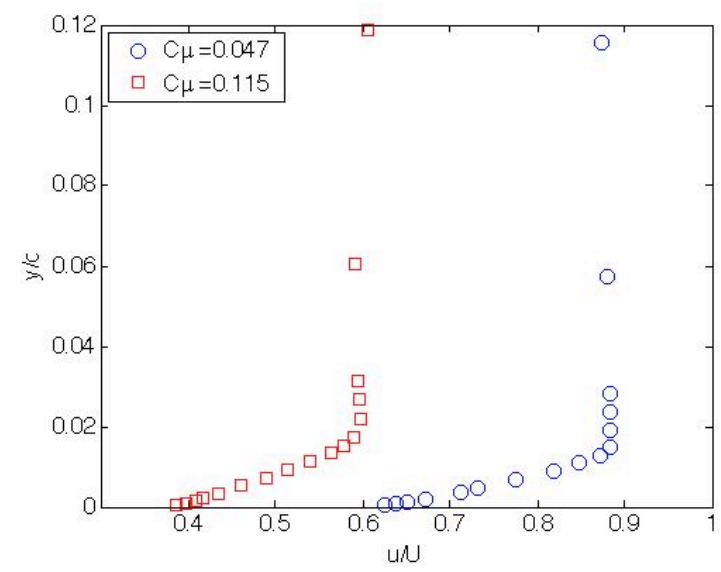

Figure 19. LDV boundary layer profiles, lower surface, $\mathbf{x} / \mathbf{c}=\mathbf{0 . 9}$.

\section{Summary}

A 2D CCW designed at GTRI under the NASA Fundamental Aeronautics Subsonic Fixed Wing Project has been tested at the BART facility at the NASA Langley Research Center. While previous testing has been geared toward performance documentation the current study has committed to provide detailed flow-field information for comparison with numerical studies. A transition study was first performed in order to determine the state of the boundary layers for jet momentum coefficients up to 0.185 . Boundary layer trips were put in place on the upper and lower surfaces and the existence of turbulent boundary layers was verified at $C \mu=0.047$ and 0.114 . Chordwise 
pressure measurements were acquired at 50\% and 75\% span, and good general agreement was seen for the higher blowing case when compared with 2D compressible RANS computations. A spanwise row of pressure orifices (x/c $=0.69$ ) was used to evaluate two-dimensionality of the flow field. Significant $3 \mathrm{D}$ effects were seen over the model at $C \mu=0.114$ suggesting that some form of juncture treatment will be needed in the future as mass-flow rates are increased. The effect of the model on tunnel static pressure has been documented and uncertainty bounds established for both blowing rates tested. An angle of attack correction to account for the net downwash caused by tunnel sidewall interactions has not yet been developed. LDV measurements were made on the upper and lower surfaces of the model at $\mathrm{x} / \mathrm{c}=0.8$ and 0.9 to document the boundary layer states. Future plans call for the integration of the current air delivery system with a seeding system to enable LDV measurements of jet-exit velocity

\section{Acknowledgments}

K. B. Paschal would like to thank Donald Day whose work in the tunnel made this study possible.

\section{References}

${ }^{1}$ Madavan, N. K., Rogers, M. M., "Direct Numerical Simulation of Flow Around a Circulation Control Airfoil,” AIAA-20104577, June 2010.

${ }^{2}$ Rumsey, C. L., Nishino, T., "Numerical Study Comparing RANS and LES Approaches on a Circulation Control Airfoil". AIAA-2011-1179, Jan. 2011.

${ }^{3}$ Jones, G. S., Viken, S. A., Washburn, A. E., Jenkins, L. N., Cagle, C. M., “An Active Flow Circulation Controlled Flap Concept for General Aviation Aircraft Applications," AIAA-2002-3157, June 2002.

${ }^{4}$ Wetzel, D., Griffin, J., Liu, F., Cattafesta, L., “An Experimental Study of a Circulation Control Airfoil Trailing Edge Flow Field," AIAA-2010-4576, June 2010.

${ }^{5}$ Englar, R. J., Blaylock, G. M., Gaeta, R., J., Jones, G. S., Millholen, W. E., "Recent Experimental Development of Circulation Control Airfoils and Pneumatic Powered-Lift Systems," AIAA-2010-345, Jan. 2010.

${ }^{6}$ Nishino, T., Shariff, K., "Numerical Study of Wind-Tunnel Sidewall Effects on Circulation Control Airfoil Flows," AIAA Journal, Vol. 48, No. 9, Sept. 2010, pp. 2123-2132.

${ }^{7}$ Allan, B. G., Jones, G. S., Lin, J. C., "Reynolds-Averaged Navier-Stokes Simulation of a 2D Circulation Control Wind Tunnel Experiment," AIAA-2011-25, Jan. 2011.

${ }^{8}$ Rumsey, C. L., Gatski, T. B., Ying, S. X., Bertelrud, A., "Prediction of High-Lift Flows Uisng Turbulent Closure Models," AIAA-1997-2260, June 1997.

${ }^{9}$ Meyers, J. F., Hepner, T. E., "Velocity Vector Analysis of a Juncture Flow Using a Three Component Laser Velocimeter," Second International Symposium on Applications of Laser Anemometry to Fluid Dynamics, July, 1984, Lisbon, Portugal.

${ }^{10}$ Paschal, K., Goodman, W., McGhee, R., Walker, B., Wilcox, P., "Evaluation of Tunnel Sidewall Boundary-Layer Control Systems for High-Lift Airfoil Testing,” AIAA 1991-3242, Sept. 1991.

${ }^{11}$ Novak, C. J., Cornelius, K. C., “An LDV Investigation of a Circulation Control Airfoil Flowfield,” AIAA-1986-0503, Jan. 1986.

${ }^{12}$ Novak, C. J., Cornelius, K. C., Roads, R. K., “An LDV Investigation of a Circulation Control Airfoil Flowfield,” AIAA1987-0155, Jan. 1987

${ }^{13}$ Coleman, H. W., Steele Jr., W. G., Experimentation and Uncertainty Analysis for Engineers, John Wiley \& Sons, Inc., New York, 1989, Chaps. 1-3.

${ }^{14}$ Wedderspoon, J. R., "The High Lift Development of the A320 Aircraft,” ICAS paper 86-2.3.2, 1986.

${ }^{15}$ Morgan, H. L., Ferris, J. C., McGhee, R. J., "A Study of Hight Lift Airfoils at High Reynolds Numbers in the Langley LowTurbulence Pressure Tunnel,” NASA TM-89125, July 1987.

${ }^{16}$ Paschal, K., Jenkins, L., Yao, C., “ Unsteady Slat-Wake Characteristics of a High-Lift Configuration,” AIAA-2000-0139, Jan. 2000.

${ }^{17}$ Obara, C. J., "Sublimating Chemical Technique for Boundary-Layer Flow Visualization in Flight Testing," Journal of Aircraft, Vol. 25, No. 6, June 1988, pp. 493-498.

${ }^{18}$ Braslow, A. L., Knox, E. C., "Simplified Method for Determination of Critical Height of Distributed Roughness Particles for Boundary-Layer Transition at Mach Numbers from 0 to 5," NACA Technical Note 4363, Sept. 1958. 